totaling \$954,231. Major developments in other areas are detailed in the Report.

The appendixes to the Report should also receive some attention. The Library of Congress, already giving incomparable leadership and service to the profession, could provide an additional service in straightening out the statistics muddle. There is much confusion among librarians concerning the total size of a library. On page $80, \mathrm{LC}$ adds up all types of units and comes up with 36,905,919 , a new high, which it calls the "Total Contents of the Library." It seems to the writer that this is a meaningless figure because volumes, microcards, microfilms, etc., are all added together. Why not add pages in books? Moreover the definition of the meaning of a volume by LC, acceptable to the profession, would resolve the contradiction in the definitions given by $C R L$ for its annual statistics and those of the Office of Education for its annual statistics. Space limitations prevent more detailed development of these comments. A minor point that may also need straightening out is the use in the LC statistics, by the reference department, of the term "items accessioned," and by the processing department, of the term "pieces processed." Is there a difference?

An important appendix to the Report is the list of notable publications of the Library of Congress for fiscal 1958, which includes the National Union Catalog, the sixth edition of Subject Headings Used in the Dictionary Catalogs of the Library of Congress, and other important titles.

The 1957-58 annual report of the Librarian of Congress is an exciting document and is recommended reading for all librarians.-Henry Birnbaum, Chief Circulation Librarian, Brooklyn College.

\section{Bible Bibliography}

Eleven Years of Bible Bibliography; the Book Lists of the Society for Old Testament Study, 1946-56. Edited by H. H. Rowley, Indian Hills, Colo.: Falcon's Wing Press [c1957, vii, 804p.

There is no disputing the primary objective of this volume which is to present a reliable and annotated bibliography of Old Testament studies during the past decade. But to leave it at that might appear as lack of.appreciation of the labors of the indefatigable and erudite editor of the volume. What is more, it might frighten away from it searching but unsuspecting and irresolute readers and reduce its usage to the mercy of cloistered scholars, theologians, librarians, teachers, preachers, etc. Not an inconsiderable conglomeration, to be sure, as far as audiences go. But the volume has an appeal much broader, and would prove very useful to a growing number of intelligent lay readers who are neophytes to Bible study. Scholars specializing in related and adjoining fields who lack the time and energy to pursue Old Testament studies in detail, will learn much about recent research on the subject.

For, strange as it may sound, the average literate layman would rarely associate with Bible study the huge amount of preparatory research work and the toil required to produce an up-to-date, readable, and meaningful translation in any modern language. Few would suspect that, in order to arrive at the exact meaning of the text, access to older versions and the minute perusal of long checklists of manuscripts are required. To penetrate beneath the transcript of the text as it reached us one would have to familiarize himself with the origin and development of writing and the attempts at decipherment. That the pottery, metals, flora and fauna, coins, buildings, temples, fortifications, and evidence gleaned from travel accounts are part and parcel of it is an undeniable, although unappreciated fact.

Few connect aerial reconnaissance with Biblical excavations. Yet to the initiated few there is no conceiving of modern archeological excavations without it. Electromagnetic detection, radio-carbon dating, and the dating of fossilized bones by fluorite content have all been utilized in the search of Biblical truth.

The normal expansion of Biblical studies through many newly erected seminaries, and the revival of Hebrew as a spoken language in the new Republic of Israel, may have contributed their share to this growing interest in the Bible. But what really brought it to the attention of millions of 
Americans and placed several volumes dealing with it on the best seller list are the Dead Sea or Judean Scrolls. This epochal discovery has given Biblical research a new impetus. The enthusiasm which it has generated among circles not previously known for their excessive attachment to such writings accounted for dozens of volumes and hundreds of articles treating in exhaustive detail every conceivable phase of it. Overnight the subject has become fashionable, a topic of conversation in good society, and a discipline worthy of further pursuit.

But at this very stage the lack of adequate preparation for the intelligent pursuit of their study became most apparent. There was no lack of basic, standard paraphernalia on the subject, such as concordances, dictionaries, grammars, textbooks, etc. But the historical implications and the evolving minutiae were apparent only to a select $\mathrm{mi}$ nority. The invaluable studies on the Bible produced in a dozen major languages and extending over all continents and climes naturally contributed to the difficulties of maintaining adequate controls over them.

The war years, the paper shortage immediately following it, and the overemphasis on other more immediate tasks caused havoc in the Bible publishing field. Only by accident did we learn of an important work published in Estonia, Finland, or some Scandinavian country shedding new light on an old problem, offering a new approach, or raising doubts about an accepted solution to some Bible questions. Great was the discomfort of a scholar or a librarian who, after spending much time and effort to secure the title of a new publication, would suddenly discover that it was no longer obtainable, that it was already out of print. And only the luxury of extensive correspondence would bring back the reply of an anxious dealer that he would continue with his efforts to secure a copy. One can, therefore, easily imagine the joy with which cognoscenti greeted the appearance of this volume. The mere initials of the internationally known savants gracing the expertly drawn up reviews avoiding excessive verbiage and stilted compliments carry weight and spell confidence in their evaluations.
A reviewer would not hesitate to point out that some contributors to a commentary designed for readers without a knowledge of the Biblical languages should consider themselves part of the audience. On a more personal note, another would remark about the weak binding in a tome designed for daily use, and conclude on a more plaintive note that "copy has already come to pieces."

And perhaps even more important than the listing and reviews of the studies devoted to individual subjects, are the volumes it names which compress within their covers a variety of treatments and topics, in succinct form, by expert hands, often reflecting the sum total of accumulated knowledge on a given area. Many such tomes, both Festschriften and memorial volumes, have resulted of late from the spreading custom of collecting into book form papers by colleagues, pupils, and friends, to mark the anniversary or death of a respected expositor, or to honor an international gathering or similar event. Most of these writings, produced during the last decade, appeared in too few copies. These limited editions, to be sure, were motivated by no other reason than innate humility. But to the perplexing question of why they received so little or no attention in the press, there is no cogent answer. Even scholars intimately connected with these various fields often find it extremely difficult to locate a desired copy. Privileged is he who receives reprints of some of the articles, upon the implicit understanding that he will reciprocate with a similarly elusive study in the not too distant future.

Everything of importance to Bible studies which appeared in book form, and with some exceptions as articles, during the past dozen years or so, whether it touch upon history and geography, exegesis and modern translations, literary criticism and introductions, including the history of interpretation, law, religion and theology, the life and thought of the neighboring people, the Dead Sea Scrolls, post-Biblical Judaism, philology and grammar, aside from more general topics, will be awaiting the conscientious peruser of this most valuable volume. -Lawrence Marwick, Library of Congress. 